A diferencia de ciertas cinematografías latinoamericanas o europeas, que han optado por dar una fuerte presencia a actores no profesionales, el cine norteamericano aún sigue creando estrellas con estudios de por medio para la interpretación de los más diversos personajes. Aquí presentamos una selección de diez actores del cine norteamericano que pueden ser muy buenos, solo buenos, o no tan buenos, pero que han tenido un rol fundamental sobre todo a partir de este nuevo milenio para mantener viva la magia del ecran en el imaginario de los cinéfilos.

\section{Heath Ledger}

Cuando Corazón de caballero pasó con justicia al olvido, dejó como rastro y único valor a un chico que podía (más que sabía) actuar. Tres años después, cuando con apretados jeans e impostada voz de macho fue un vaquero homosexual, este mismo chico ofrendó a la industria de Hollywood la confirmación de un joven actor cabal, con garbo de galán, (in) creíble en sus máscaras de rodaje. No hubo tiempo para maquinar la vendible expectativa de una promesa actoral o la del guapo del nuevo siglo, el talento de Heath Ledger, debutado ante las masas en Secreto en la montaña, derogó -por su inmediata eclosión-cualquier procedimiento de mercadeo alrededor de su figura; no demostró lo que podía llegar a ser o a emocionar, sino que estableció su invariable estatus de artista -no de divo- con una manifestación sola.

Ennis del Mar, personaje sufriente de una ambigua vida sentimental, pareció marcar la pauta de su perfil como intérprete: gallardo pero sentimental, afligi- do de gesto y apasionado como amante; características de actor sensible para dramas románticos. Qué gusto confirmar después el error de nuestro prejuicio, pues, antes de irse, daría la muestra definitiva de su versatilidad como sentida despedida, en la que utilizaría su más inolvidable máscara.

Esa última degeneró al más perturbador rostro en pantalla grande de los últimos años pasados, el de un payaso asesino por placer al caos, el de un delirante e histriónico agente del desorden: el Joker; la imagen definitiva como será recordado por quienes gozamos (por muy poco tiempo) de su genio. El Joker de Ledger es la insignia de Batman: El caballero de la noche, el signo de su éxito y principal atractivo de su largometraje. Sus pasos y frases enrostran nuestra ambigüedad de acción y distinción acomedida del bien y el mal, el Joker es la encarnación de nuestras pulsiones malévolas. La faz de Ledger deformó al de las intenciones malditas del hombre, y eso lo hace más entrañable por nebuloso.
El sinsabor de la frustración fastidia su recuerdo. Qué tanto más pudo dar su sensibilidad para interpretar, su facultad para hacer memorable su gesto dramático. La respuesta quedó trunca. En adelante se hablará de Heath Ledger en tiempo pasado; medito recién si todo tiempo pasado fue mejor.

Campos Gómez

\section{Scarlett Johansson}

Fotogénica desde el nombre, Scarlett Johansson se ha convertido en una importante actriz en Hollywood. Sin embargo, ninguna de las películas en las que ha participado ha generado ingresos mayores a los sesenta millones de dólares. Más bien ha elegido papeles de cine independiente, en lugar de convertirse en una de esas acompañantes del protagonista. La jugada le ha funcionado.

Si lo pensamos bien y superamos su impresionante presencia, nos daremos cuenta de que no es una actriz particularmente expresiva. Ese rostro suyo 
que no exagera ninguno de sus gestos la podría convertir, en una broma cruel, en la Paris Hilton de Hollywood: guapa, poderosa y con un rostro impenetrable. Johansson lo sabe y por eso prefiere el cine independiente. El efecto es tan arrollador como ver a la Hilton en una granja, fuera de su elemento. Johansson se mueve bien allí, donde todos la estamos mirando. Prefiere ser la cabeza de un filme independiente que la cola de una película multimillonaria.

Esto podría ser una desventaja en el futuro, pero no ahora. Lo que la hace tan interesante es que la vemos así, con ese rostro duro como un palo y somos nosotros quienes pensamos que debe tener mil cosas en la cabeza. Lo que salva a Johansson es su porte. No tanto su belleza sino su presencia. Ya desde The horse whisperer, en la cual aún es pequeña, se nota esta contención. Nos hace creer que está por explotar, que es una niña engreída a la que más nos vale darle gusto. Probablemente lo sea hasta ahora.

Ella juega con eso. Ha perfeccionado la técnica de la contención hasta volverse una mujer terriblemente deseable. Con los años se ha vuelto bellísima y sin embargo ella sigue así, inexpresiva, impenetrable. Seriedad absoluta o uno que otro gesto minúsculo. Más, no le vamos a sacar.

El consejo para esta niña: que no haga circo, comedia ambulante, ni ninguna disciplina que involucre una pizca de exageración. Ella es aguantada y compleja, y así nos gusta. No sabemos cuántos papeles más queden en Hollywood para ella, pero quisiéramos que los hubiera. Frank Miller, quien la ha dirigido recientemente, ha declarado que piensa que Johansson es una Lucille Ball joven. Si está en lo cierto, Scarlett Johansson nos traerá sorpresas también la próxima década.

Casuso

\section{Viggo Mortensen}

De la interculturación nace un actor camaleónico capaz de de interpretar roles para Brian De Palma (Carlitos Way), Peter Jackson (El Señor de los Anillos) o David Cronenberg (Una historia violenta, Promesas peligrosas), entre otros. Incluso migrando hacia el mercado hispano los filmes Gilmet de José Luis Acosta, y la reciente Alatriste de Agustín Díaz Yanes. Demostrando así su capacidad de actuar en ambas lenguas, con la misma intensidad. Si bien desde la epónima obra de Peter Jackson, Mor- tensen alcanzó más notoriedad, su carrera había atravesado altibajos, con papeles menores que no le permitían demostrar su capacidad de representación.

Con David Cronenberg, su nombre se hizo más fuerte en la industria. Desde ese entonces, el registro del tipo rudo, o el tipo imperdonable, empezó a cobrar vida con él. Los giros de Una historia violenta permiten observar a un actor que sabe controlar su ira ante cámaras. Sarcástico y con garbo, es la evolución del "cara bonita" en un vengador sanguinario. $\mathrm{Al}$ igual que en Promesas peligrosas, donde interpreta a un agente encubierto del FBI, infiltrado en las entrañas de la mafia rusa de Nueva York. El arquetipo fabulesco del "bueno" cambia y los cánones ya no son los mismos; este puede desaparecer cuerpos, ya sea descuartizándolos o arrojándolos al río. Es interesante mencionar que Mortensen preparó su personaje de Promesas peligrosas interactuando por mucho tiempo con sujetos marginales de la ex Unión Soviética, y vaya que con ello logró darle gran forma a su personaje.

A pesar de ello, no se limita a la actuación. Después de haberse graduado en política y español, su eclecticismo hace que se expanda hacia horizontes diversos como la poesía, la fotografía y la música. Justamente en esta última es donde mayor notoriedad ha tenido, incluso musicalizando algunas escenas de su personaje en El Señor de los Anillos.

Cuevas

\section{Naomi Watts}

Si bien la carrera de esta actriz inglesa empieza en el cine y la televisión mucho antes del 2000, recién obtuvo una popularidad de alcances mundiales en este nuevo milenio. La figura de Naomi Watts, con sus gestos suaves, con la belleza casi enjuta de su cuerpo, con sus ojos de aura inocente, se ha convertido en muchas de sus películas (a pesar de sus imperceptibles cuarenta años) en una Alicia frágil, de eterno espíritu infantil, como la de los relatos de Lewis Carroll, enfrentada a situaciones absurdas, insólitas, retorcidas, en las que las pesadillas cobran vida, en las que los sueños más macabros e infernales se materializan, se hacen palpables, se pueden tocar.

Hay, en muchas de las actuaciones más conocidas de Watts, una ingenuidad que se desvanece, se apaga, ante la revelación de un mundo perverso. Es la cándida Betty que termina uniéndose a Rita en uno de los momentos de erotismo onírico más lascivos que se recuerde en la historia del cine en El camino de los sueños (2001); es la Rachel que se enfrenta a la truculenta historia de un fantasma que se apodera de aparatos de video en El aro (2002); es la actriz que finalmente ama a un gorila gigantesco, y que tiene que soportar la crueldad del mundo moderno en King Kong (2005); es la confiada partera que descubre que la familia de un ruso amable esconde una mafia salvaje en Promesas peligrosas (2007); es la educada madre que finaliza sus días humillada, vejada, atada y tirada al mar por dos jóvenes y sofisticados psicópatas en el remake norteamericano de Funny games (2007), dirigida por el mismo Haneke.

Y en medio del halo de candor, de pausa británica, que acompaña a las actuaciones de Naomi Watts, igual sentimos las emociones más recónditas en su cuerpo. Pocas actrices han transmitido el dolor con tanta intensidad a través de la quietud, de la calma, del lento andar. Su rostro se estremece con el sentimiento de sus personajes, como si hubieran cobrado vida ante nuestros ojos, como si la hubieran poseído. Sus interpretaciones de la Diane Selwyn, su "segundo" personaje en El camino de los sueños, o de Cristina Peck en 21 gramos (2003) son formidables en su representación de mujeres que deambulan como almas en pena, que padecen una angustia sonámbula, que las hiere cuando despiertan y también cuando duermen.

José Carlos Cabrejo

\section{Paul Giamatti}

Él nos recuerda que no todos los héroes son de plástico ni deben tener un peinado perfecto. Desde comienzos de la década ha estado construyendo protagonistas llenos de nervios y culpas. Ya sea interpretando críticos, escritores o cineastas; la mayoría de sus filmes muestran a personajes dubitativos que deben encontrar sus historias. Incluso en papeles más arquetípicos - como el que hace en El ilusionista- siempre hay en sus personajes una humanidad ingenua, capaz de darle realidad a las ilusiones.

Sus herramientas son un seseo en la voz, un rostro bonachón y su comportamiento nervioso. Él es algo así como un cruce entre Woody Allen con Kevin Spacey. Un tipo que podríamos encontrar alquilando videos en pleno Año Nuevo, haciendo lo imposible por no parecernos raro. Hay un lado de Paul Giamatti que da lástima, que parece tan vulnerable como para hacernos temer que en cualquier momento va a salir corriendo, avergonzado. 
A diferencia de otros actores que deben darle humanidad a sus héroes, Giamatti debe hacer lo opuesto, convencernos que un don nadie también tiene dotes heroicas. Como espectadores, lo primero que notamos en él son sus imperfecciones: una calvicie temprana, su cuerpo de pera, la inevitable miopía. Después, él logra que la expresividad de su rostro y su dicción gutural, lo transformen en un héroe improbable, que lucha por sus objetivos. Esto ocurre en filmes como Esplendor americano y Entre copas, sus mejores interpretaciones de la década.

Sus problemas empiezan cuando en lugar de interpretar a personajes realistas, se anima a construir uno más estereotipado. Esto último ocurre en La huida, donde su participación parece incluso atentar contra la historia. El sicario de esa película debió ser tan típico como el de cualquier filme de acción. Su interpretación realista, en cambio, raya con el ridículo.

Consejos para la próxima década de Giamatti: nunca ceder a la tentación de liposucciones ni injertos de cabello. Estudiar de cerca el comportamiento de gallinas, ardillas y demás especies neurasténicas. Evitar personajes estereotipados que se vuelvan inmanejables por un actor que nos resulta demasiado humano. Sus mejores cualidades no se hallan en sus dotes actorales ni en su aura de gruñón simpático. Su mayor fortaleza radica, contradictoriamente, en parecernos vulnerable.

Casuso

\section{Keira Knightley}

Me gusta creer que Keira Knightley es una figura del pasado más que una actriz. Será porque las imágenes de Elizabeth Bennet (Orgullo y prejuicio) y de Cecilia Tallis (Expiación) son las únicas que vienen a mi mente cuando escucho su nombre. Señoritas de sociedades pasadas, con porte principesco y finura encantadora, románticas de verso y de diligente paciencia, tan agradables a la vista como al oído. Retratos refinos - ambos responsables de Joe Wright, que sirvió provechosamente del semblante de su bello fetiche-, propios de la pretérita dama inglesa que proyecta ser.

Esa elegante figura del pasado se pervierte cuando se interponen sus fallos curriculares como cazarrecompensas (Domino), apasionada pirata (Piratas del Caribe) y reina guerrera de la Mesa Redonda (Rey Arturo), intentos vacuos de hacer industria, dañosos a su evocable imagen, la de cuando de seda viste.

Su perfil de damisela enamorada, defendido en estas líneas, es consecuencia
Dato: Heath Ledger también obtuvo este año el premio Robert Altman en el Independent Spirits Awards por su papel en I'm not there, cinta

\section{basada en la vida de Bob Dylan.}

de sus picos en las cintas de época de Wright, haciendo una disyuntiva de su versatilidad actoral, queriendo demostrarla con rudeza en más de una ocasión con olvidables resultados. Como en la trilogía de los piratas caribeños, desfile de pirotecnia al servicio de las maromas de Jack Sparrow, en la que su personaje, Elizabeth Swann, es apenas decorativo. En Domino, videoclip dilatado de vértigo mareador, opta por las armas y la violencia con impostado descaro en pos de recompensas. Por otro, el arco y la flecha le sirven como indumentaria del disfraz de Guinevere en la épica y traficada Rey Arturo. Tres incursiones con requerimientos físicos que poco y nada exigen al talento interpretativo, sea cual fuere el caso, asistiendo a las asentadas demandas de la industria de los rostros, Hollywood, que aprovecha cada margen para corromper con su caudal.

Menos sonados son los casos preWright de Quiero ser como Beckham, considerada su vitrina, y Realmente amor, películas menores de importancia secundaria en su filmografía, con las que aporta poco más que su sonrisa en sus alternadas apariciones primeras.

El 2008 regresaría nuevamente en el tiempo para encarnar a Georgiana Cavendish, duquesa de Devonshire, ícono de la frivolidad del siglo XVIII, en $L a$ duquesa, confirmando que su estatus "de época” está enlazándosele. No soy el único que sigue creyendo que Keira Knightley es una figura romántica del pasado.

Campos Gómez

\section{Colin Farrell}

El irlandés Colin Farrell es una figura de la década tal como lo fue Brad Pitt o Tom Cruise en su momento. Es un actor sumamente atractivo por lo cual sus performances son tomadas con reticencia, como si se despertara la desconfianza al verlo como Alexander, Jesse James o el capitán Smith, personajes históricos que parecieran sobrar bajo su fisonomía. Sin embargo, Farrell ha demostrado ser más un actor de presencia que de exigentes interpretaciones a lo Actor's Studio, y que con papeles como Enlace mortal de irregular Joel Schumacher (con quien ya había trabajado en Tigerland como un soldado medio irreverente antes de ir a Vietnam, en su debut como actor en Estados Unidos allá por el año 2000), el Sonny Crockett de Miami Vice del impecable Michael Mann o el Terry de Sueños y delitos de Woody Allen, ha demostrado que tiene talento para rato.

Farrel se convirtió durante la última década en un actor requerido de Hollywood (apareciendo hasta en más de tres películas por año), pero también en uno de los rostros típicos de los blockbuster de fin de semana, predominando sus papeles protagónicos en filmes como S.W.A.T. (2003), The recruit (2003) con Al Pacino o la misma Alexander, la épica mastodóntica de Oliver Stone. Ha trabajado con Terence Malick, Steven Spielberg, y los ya mencionados Mann, Allen, Stone, Schumacher. Hasta la fecha, encarnar al capitán Smith en El nuevo mundo ha sido su mejor papel.

Farrell es un actor que ha actuado en películas de casi todos los géneros, desde el policial de suspenso hasta el drama familiar, como en La casa al final del mundo (2004), del filme histórico hasta el thriller o el western (como en American Outlaws del 2001). Ha desarrollado papeles secundarios en diversos filmes fantásticos como Minority Report o Daredevil, donde lo vemos como villano. Es un actor que ha sabido cuidar aspectos de su carrera y centrarse en filmes que ponderen su imagen de actor recio que requieren los filmes de acción y policiales. Hasta ahora no lo hemos visto en películas románticas o de terror, ya que al parecer no son parte de su interés actoral.

Este año 2009 lo veremos por lo menos en cuatro filmes, entre ellos la obra que dejó inconclusa Heath Ledger, The imaginarum of doctor Parnassus de Terry Gilliam, y en la también fantástica Ondine de Neil Jordan. Ya se anuncia para el 2011 su participación en el 


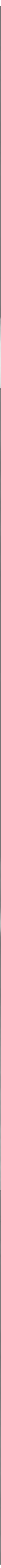


nuevo proyecto del australiano Peter Weir, titulado The way back, una cinta bélica donde actuará junto a Ed Harris, que lo reencontrará con la temática que lo lanzó a la fama en Hollywood.

Delgado

\section{Cate Blanchett}

Muchos la identifican como Galadriel en la serie de El Señor de los Anillos, pero tal vez sea mejor admirar el contraste entre su figura frágil y piel de alabastro, casi transparente, con la determinación y fortaleza de los personajes que le tocaron en suerte, desde la reina Isabel I de Inglaterra hasta la Katharine Hepburn de El aviador. Pero a diferencia de Kate, la irlandesa testaruda, esta Cate australiana no parece interesarse por la comedia de situaciones, salvo que el humor sea de segundo grado, cerebral y distanciado, como en Vida acuática u oblicuo e involuntario, como en Indiana Jones en el reino de la Calavera de Cristal. La agente soviética que allí encarna no está muy alejada del tipo de papeles que prefiere: los que exigen el transformismo físico y emocional. Y en ese rubro no solo está su representación de Hepburn, con caminata altiva y empeño de mujer hawksiana, sino su acercamiento mimético a Bob Dylan en su fase de niño-viejo enfurruñado en I'm not the$r e$. El pasaje que interpreta es lo mejor de esta película ambiciosa que ve a Dylan como una hidra simbólica del ser norteamericano del siglo XX.

A Cate Blanchett se le ve cómoda y desenvuelta mandando, disponiendo y hasta sufriendo, como en Escándalo o Babel, ese monumento al golpe de pecho programado y al dolor de corazón globalizado, pero no encaja en El buen alemán, donde Soderbergh la quiere convertir en heroína de un drama romántico de los años cuarenta al lado de George Clooney. Esa vía no le conviene. Hay en Cate un costado temperamental, indómito, insumiso, autosuficiente, una pizca exhibicionista, que no tolera ni admite la presencia de un hombre fuerte en los alrededores. Ella no es muñeca de vitrina ni comparsa de cualquier actor de moda. Es como una Bette Davis levantisca con ganas de torturar u opacar al Erroll Flynn que se pare al lado.

Ricardo Bedoya

\section{Paul Dano}

A pesar de su relativamente corta carrera como actor, Paul Dano destaca como un intérprete secundario muy dotado para el drama e incurso en los senderos de la técnica externa. Su misma composición transparente $\mathrm{y}$ moralmente nívea, lo llevan a apostar estratégicamente por los flancos más indefensos y endebles de su personalidad; dilatándolos al máximo pero sin que medie queja o afectación, a efectos de retener y embalsar una energía contradictoria, malsana, chirriante en ocasiones, que al desbordarse tiene consecuencias telúricas. Así, los adolescentes y jóvenes compuestos por Paul Dano se caracterizan por soportar silenciosamente sus circunstancias, su enemistad con la vida, sus fracasos y "sacadas de vuelta", asumiendo frontalmente su condición de parias, psicópatas asesinos o golfos. Educado entre Manhattan y Connecticut, este actor teatral afincado en Nueva York interpretó papeles secundarios en prestigiosas producciones de Broadway, verbigracia Inherit the wind (Heredarás el viento) y A month in the country (Un mes en el campo). Su debut cinematográfico fue en el drama de iniciación a la vida adulta, L.I.E. (Michael Cuesta, 2001) con el cual Dano ganó un Premio Espíritu Independiente. Un misterioso asesino sin rumbo (Vidas ajenas, D. J. Carusso, 2004); el hijo de un pastor cristiano, víctima inocente de un crimen absurdo (The king, James Marsh, 2005); un depredador sexual obsesionado con una adolescente (The ballad of Jack and Rose, Rebecca Miller, 2005) y un adolescente pasivo que trabaja a destajo en un restaurante de comida rápida (Fast food nation, Richard Linklater, 2006) son registros bastante matizados dentro de una carrera con tendencia a capitalizarse, a tenor de un estilo fungible y práctico.

La consagración mundial de Paul Dano llegaría con la comedia indie Pequeña Miss Sunshine (Jonathan Dayton y Valerie Faris, 2006) en la que comparte reparto con Alan Arkin, Abigail Breslin, Steve Carell, Toni Collette y Greg Kinnear. Su interpretación como un muchacho entregado al ejercicio físico y a Nietzsche, que ha hecho voto de silencio y del nihilismo una balsa, es estupenda y le valió muchos premios. Al igual que su performance en Petróleo sangriento (Paul Thomas Anderson, 2007) en donde construye dos personalidades gemelas (los hermanos Paul y Eli Sunday) totalmente desbordadas, fanáticas, ambiciosas; y, por lo mismo, vulnerables. Paul Dano es nuestra apuesta ganadora para la siguiente década.

\section{Hillary Swank}

El día que Hillary Swank se meta en política, nadie va a votar por ella. Es una de esas actrices que hacen lo imposible por mantenerse indefinidas. Desde su filme emblemático de esta década, Golpes del destino, ella se ha presentado así, con una cara que no es un rostro sino una transición. La eterna adolescente torturada. Esta chica más que una actriz, es un transformer.

Cuando hemos estado por definirla ella ha encontrado un papel que nos descuadra (Freedom writers). De pronto, nos damos cuenta de que no es fea. Obviamente, tampoco es bonita. Mucho menos la alternativa que nos queda: Swank no tiene en lo absoluto una pinta normal.

Tiene un rango actoral que nos intimida como espectadores. Por su rostro pueden pasar las emociones más extremas. Curiosamente no es una actriz con demasiada presencia corporal. Es más bien enclenque, una delgadez humana. Esto resulta particularmente interesante en un filme como Golpes del destino, en el que sabemos cuál va a ser su final. Sabemos que habrá otras boxeadoras que la aventajarán físicamente. Claro que Swank nos confunde antes de que podamos definirla. Cuando estamos por decirle "alfeñique", nos muestra unos bíceps y tríceps dignos de El Club de la Pelea.

Ella es así, difícil e inconforme. Siempre metiéndose en situaciones límite, haciéndonos creer que las va a saber manejar, para las cuales parece haberse preparado. Pero también siempre con esos finales trágicos.

Esa sensación de que es una actriz sin presencia, nunca nos abandona como espectadores. Pero tenemos la esperanza de que haya aprendido la lección. Ese es el gran talento de Swank, hacernos creer que va a salir adelante. Ese es el juego que trae a la mesa esta actriz.

Si hay algo que sí podría definirla, es que se ve inteligente. $Y$ sus decisiones como actriz lo confirman. Swank nunca preferirá un gesto cliché a uno sincero, siempre nos mostrará esos rostros que parecen debatirse ante cada circunstancia, jugará con esa voz que le puede sonar quebrada en ocasiones y heroica en otras.

Consejos para Hillary: quedarse con las tragedias. Las de heroínas luchadoras que en la puerta del horno se queman. Ella tiene esa capacidad de hacernos creer que no va a perder, pero en el fondo sabemos que tampoco podría ganar. 